\title{
GRAIN SIZE DEPENDENCE OF CRITICAL CURRENT DENSITIES IN HOT ISOSTATICALLY PRESSED $\mathrm{SnMo}_{6} \mathrm{~S}_{8}$
}

\author{
L.A. Bonney† T.C. Willis $\ddagger$ and D.C. Larbalestier $\ddagger$ \\ Applied Superconductivity Center \\ † Materials Science Program \\ $\ddagger$ Materials Science and Engineering Department \\ University of Wisconsin - Madison \\ 1500 Johnson Drive, Madison, WI 53706
}

\begin{abstract}
The dependence of critical current density on the heat treatment and microstructure of $\mathrm{SnMo}_{6} \mathrm{~S}_{8}$ was systematically studied. Powders with minimal initial oxygen contamination were processed by hot isostatic pressing at $800^{\circ} \mathrm{C}$ to produce a sample having a mid-point inductive critical temperature of $14.2 \mathrm{~K}$, a magnetization critical current density of $820 \mathrm{~A} / \mathrm{mm}^{2}(9 \mathrm{~T}, 4.2 \mathrm{~K})$ and electromagnetically non-granular behavior. The microstructure was controlled by varying subsequent heat treatment temperature and time and was examined by scanning and transmission electron microscopies. In each sample grains appeared well-connected and ranged over two orders of magnitude in size, with average grain sizes being between 0.2 and $0.5 \mu \mathrm{m}$. Critical current density decreased with increasing annealing temperature and time and at fields $<8 \mathrm{~T}$ was inversely proportional to the grain size. These results show that Chevrel phase materials are not intrinsically weaklycoupled and that grain boundaries are sites of Abrikosov vortex pinning.
\end{abstract}

\section{INTRODUCTION}

Interest has been recently renewed in the Chevrel phases (CP) for high field applications. [1] The key need is to raise the critical current density, $J_{c}$, in the high-field range, above 15 Tesla, where the $J_{c}$ of $\mathrm{Nb}_{3} \mathrm{Sn}$ falls rapidly. Although $J_{c}$ values continue to increase with improved processing techniques, increases of about 2 to 5 times the current values are still needed. [2] Thus, determining the factors which control the $J_{c}$ of CP materials has become the subject of intense investigation. Weak coupling between grains has been observed by a number of authors. [3, 4] Consequently, there was concern that $\mathrm{CP}$ are intrinsically electromagnetically granular, as is the concern with hightemperature superconducting (HTS) materials. However, it has been demonstrated that poorly connected grains can be converted to well-connected grains by hot isostatic pressing (HIP). [4,5] Karasik et al. [6] and Rossel et al. [7] found evidence that $J_{c}$ increased with decreasing grain size in bulk $\mathrm{PbMo}_{6} \mathrm{~S}_{8}$ samples prepared by different methods. These results suggested that $J_{c}$ may be controlled by flux pinning at the grain boundaries. The present study investigates, systematically, the microstructural dependence of $J_{c}$ in fully-compacted, bulk CP which exhibited strongcoupling behavior.

Manuscript received August 24, 1992.

\section{EXPERIMENTAL METHODS}

Because oxygen contamination is known to depress the critical temperature, $T_{c}$, in $\mathrm{CP}$, [8] the material was handled in an inert atmosphere of $\mathrm{N}_{2}$ and was reacted in evacuated and sealed quartz glass. $\mathrm{SnMo}_{6} \mathrm{~S}_{8}$ was made by mixing elemental powders (Mo powder de-oxygenated with flowing $\mathrm{H}_{2}$ at $1000^{\circ} \mathrm{C}$ ) in a stoichiometric ratio and reacting $20 \mathrm{hr}$. at $420^{\circ} \mathrm{C}$, followed by a $10 \mathrm{hr}$. ramp to $530^{\circ} \mathrm{C}$. The material was reacted at $530^{\circ} \mathrm{C}$ until only black or grey powders, presumably $\mathrm{MoS}_{2}, \mathrm{SnS}$, and Mo, remained. These powders were ground, cold isostatically pressed (CIP), and wrapped in $\mathrm{H}_{2}$-cleaned $\mathrm{Mo}$ foil. This powder compact was encapsulated with a getter $\left(\mathrm{Y}_{2} \mathrm{~S}_{3}\right.$ wrapped in $\left.\mathrm{Mo}\right)$ and reacted $100 \mathrm{hr}$. at $800^{\circ} \mathrm{C}$ to form $\mathrm{SnMo}_{6} \mathrm{~S}_{8}$. The compact was ground to a powder, CIP'ed, wrapped in Mo foil, encapsulated under a vacuum $<5 \times 10^{-6}$ Torr in stainless steel and HIP'ed for 8 hours at $800^{\circ} \mathrm{C}$ and 2 kbar. After HIP'ing, the sample was cut into smaller pieces that were subsequently annealed with getters at $1000^{\circ} \mathrm{C}$ or $1150^{\circ} \mathrm{C}$ to promote grain growth.

Samples were characterized by a.c. susceptibility and d.c. magnetization measurements. The magnetic moment of each sample was measured in a vibrating sample magnetometer (VSM) with a swept background magnetic field of 0-12 T. Critical current density was determined from the critical state model: $J_{c}=3 \Delta M / \ell$, where $\Delta M$ at a given applied field is the magnetization hysteresis and $\ell$ is the characteristic length over which shielding currents circulate. $\ell$ was defined as: $\ell=1.5 \ell_{1}\left(1-\ell_{1} / 3 \ell_{2}\right)$, where $\ell_{1}<\ell_{2}$ and $\ell_{1}$ and $\ell_{2}$ are the sample dimensions perpendicular to the applied field. $J_{c}$ may also be estimated from $\Delta H / \ell$, where $\Delta H$ is the field range needed to invert the critical state when the external applied field is reversed. The ratio $J_{c}(\Delta H) / J_{c}(\Delta M)=\Delta H / 3 \Delta M$, is unity for a wellconnected sample, and deviations greater than a factor of 2 indicate granular behavior. [9] This value was calculated to test for granularity.

Powdered samples were analyzed by x-ray diffractometry (XRD) to identify the phases present. Microstructure of polished samples was observed in the scanning electron microscope (SEM) by secondary (SEI) and backscattered (BEI) electron imaging. Samples were thinned to electron transparency and imaged in the transmission electron microscope (TEM). Sample chemistry was probed by energy-dispersive $\mathrm{x}$-ray (EDX) analysis in both SEM and TEM. From TEM images, grain boundary length per unit 
Table 1: Experimental results.

\begin{tabular}{|c|c|c|c|c|c|c|c|c|c|c|c|}
\hline \multirow{2}{*}{$\begin{array}{l}\text { Sample } \\
\text { Name }\end{array}$} & \multicolumn{2}{|c|}{ Heat Treatment } & \multirow{2}{*}{$\begin{array}{l}\text { Other Phases } \\
\text { (XRD) }\end{array}$} & \multicolumn{2}{|c|}{$T_{c}[\mathrm{~K}]$} & \multicolumn{2}{|c|}{$J_{c_{m}}\left[\mathrm{~A} / \mathrm{mm}^{2}\right]$} & \multicolumn{3}{|c|}{$\Delta H / 3 \Delta M$} & \multirow{2}{*}{$\begin{array}{c}\text { g.b. length/u.a. } \\
L_{g b}\left[\mu \mathrm{m}^{-1}\right]\end{array}$} \\
\hline & $\mathrm{T}\left[{ }^{\circ} \mathrm{C}\right]$ & $\mathrm{t}[\mathrm{h}]$ & & $T_{\text {con }}$ & $\Delta T_{c}$ & $4 \mathrm{~T}$ & $9 \mathrm{~T}$ & $4 \mathrm{~T}$ & $8 \mathrm{~T}$ & $12 \mathrm{~T}$ & \\
\hline T0 & - & - & $\overline{\mathrm{Mo}, \mathrm{MoS}_{2}}$ & 14.3 & $<0.2$ & 1770 & 820 & - & - & 0.9 & $4.0 \pm 0.6$ \\
\hline $\mathrm{T} 1$ & 1000 & 20 & Mo & 14.3 & $<0.2$ & 1490 & 700 & $=$ & $=$ & 0.5 & .6 \\
\hline $\mathrm{T} 2$ & 1000 & 100 & - & 13.3 & 0.8 & 1170 & 500 & 0.7 & 0.9 & 0.8 & $3.3 \pm 0.5$ \\
\hline $\mathrm{T} 3$ & 1150 & 50 & Mo & 13.6 & 0.3 & 780 & 500 & 0.6 & 0.9 & 1.8 & $2.3 \pm 0.4$ \\
\hline$\overline{\mathrm{T} 4}$ & 1150 & 250 & $=$ & 14.3 & 0.3 & 720 & 520 & 0.7 & 0.8 & 0.8 & $2.1 \pm 0.2$ \\
\hline
\end{tabular}

area $\left(L_{g b}\right)$, which is directly analogous to inverse grain size $(1 / d)$, was calculated as a measure of grain boundary density in each sample.

\section{RESULTS}

Samples were studied in five post-HIP heat treatment conditions as specified in Table 1.

\section{Electromagnetic Characterization}

The susceptibility data measured in an a.c. field, $B_{a c}$, of $940 \mu \mathrm{T}$ at $103 \mathrm{~Hz}$ are plotted in Fig. 1. Values of $T_{c}$ onset and width, estimated as $10 \%$ to $90 \%$ of full screening, are tabulated in Tab. 1. For samples other than T4 the decrease in $T_{c}$ with increasing $B_{a c}$ between 1 and $940 \mu \mathrm{T}$, was $<0.2 \mathrm{~K}$, and the shapes of the transitions remained the same. In T4 the low temperature part of the transition behaved similarly and a high temperature kink became less distinct, as $B_{a c}$ increased.

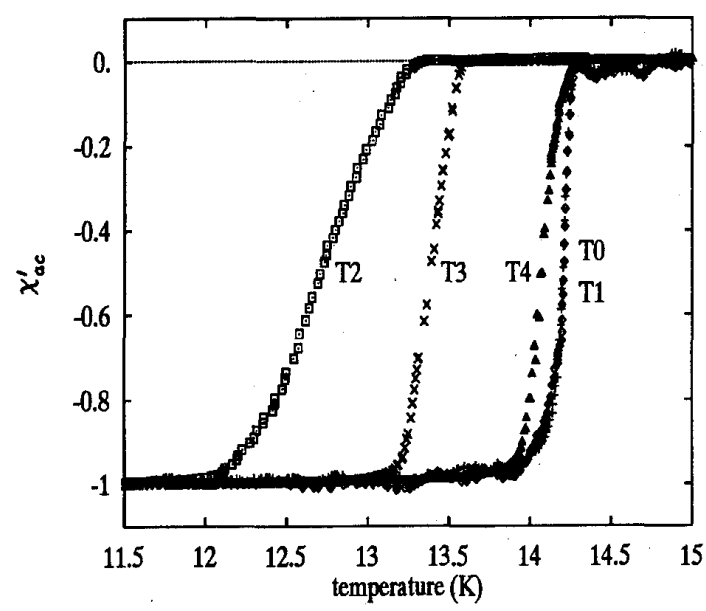

Figure 1: Susceptibility measured in a $940 \mu \mathrm{T}$ (zero to peak), $103 \mathrm{~Hz}$ a.c. field for five $\mathrm{SnMo}_{6} \mathrm{~S}_{8}$ samples HIP'ed at $800^{\circ} \mathrm{C}$ and given different post-HIP thermal treatments.

Magnetization $J_{c}$ is plotted as a function of magnetic field in Fig. 2. Measurements were made at $4.2 \mathrm{~K}$ for $\mathrm{T} 0$, $\mathrm{T} 1$ and $\mathrm{T} 4$ and at $3.9 \mathrm{~K}$ for $\mathrm{T} 2$ and $4.0 \mathrm{~K}$ for $\mathrm{T} 3$. Thus, each samples was tested at the same reduced temperature, $t=T / T_{c}=0.3 . J_{c}(9 \mathrm{~T})$ was $820 \mathrm{~A} / \mathrm{mm}^{2}$ in the sample asHIP'ed and decreased to as low as $500 \mathrm{~A} / \mathrm{mm}^{2}$ with subsequent annealing. At fields less than $8 \mathrm{~T}, J_{c}$ decreased with increasing anneal time and temperature. $J_{c}$ ranged from 730 to $1170 \mathrm{~A} / \mathrm{mm}^{2}$ at $4 \mathrm{~T}$. For all samples $\Delta H / 3 \Delta M$ fell between 0.5 and 1.8 at fields between 4 and $12 \mathrm{~T}$ (Table 1 ).

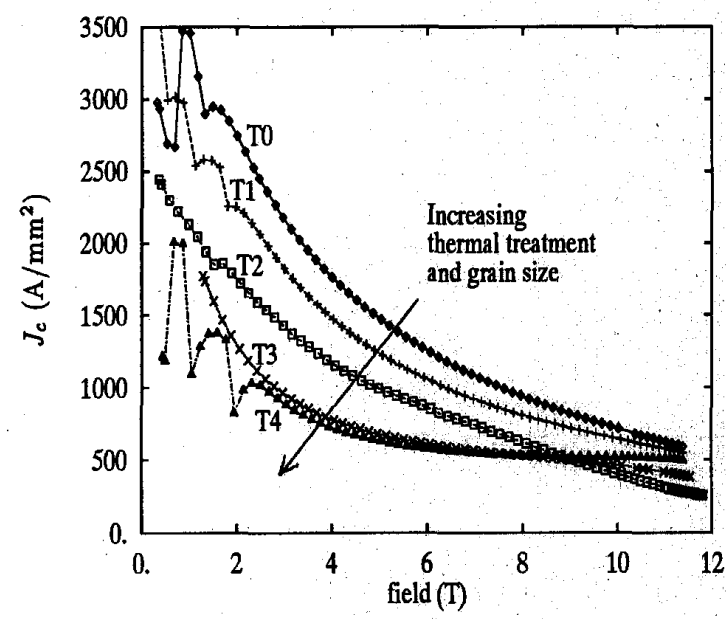

Figure 2: Magnetization $J_{c}$ measured at $4.2 \mathrm{~K}$ for samples $\mathrm{T} 0, \mathrm{~T} 1$ and $\mathrm{T} 4$ and measured at 3.9 and $4.0 \mathrm{~K}$ for $\mathrm{T} 2$ and T3, respectively. $T / T_{c}$ was held at 0.3 so as to be the same for all.

\section{Microstructural Characterization}

By XRD, T0, T1, and T3 showed evidence of phases other than CP (Tab. 1). In all samples, SEM-BEI showed a bright, higher atomic number phase, which decreased in size and density with more aggressive heat treatment. EDX indicated that these regions were composed of Mo and, possibly, $\mathrm{S}$. The relative amounts of Mo and S could not be determined because the S- $\mathrm{K}_{\alpha}$ overlapped the $\mathrm{Mo}_{\mathrm{o}} \mathrm{L}_{\alpha} \mathrm{x}$ ray peaks. A phase that appeared dark and striated by BEI was observed in samples annealed at $\leq 1000^{\circ} \mathrm{C}$. The dark regions were too small to isolate for EDS analysis in the SEM. Smaller dark regions in the $1150^{\circ} \mathrm{C}$ samples resulted from depressions in the samples' surfaces. 
TEM images of these materials showed high- and lowangle grain boundaries, some porosity and intragranular defects such as twins, stacking faults and dislocations (Fig. 3a). Grain boundaries appeared largely coherent and free of second phase (Fig. 3a and b). By TEM a phase that appeared striated was shown by EDX analysis to contain Mo and, possibly, S, but no Sn.
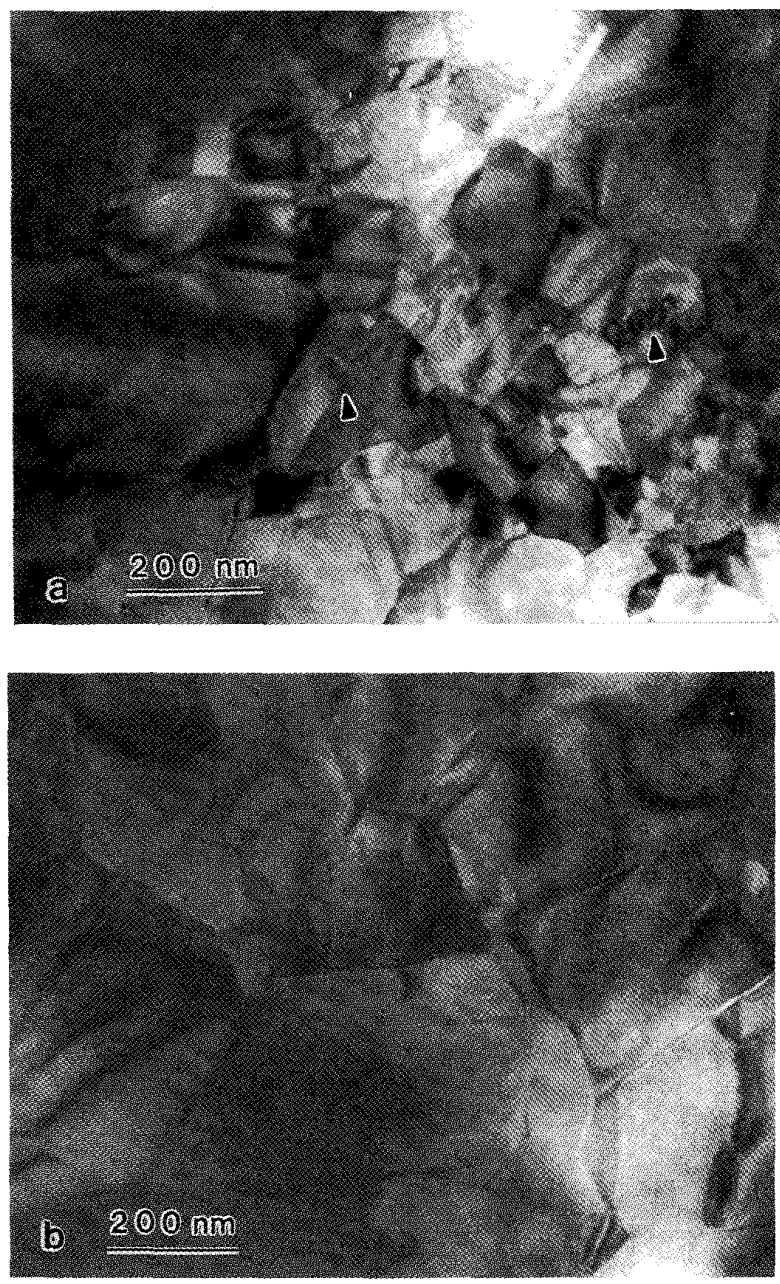

Figure 3: TEM micrographs of (a) T2 showing wellconnected grains and intragranular defects, twins (left pointer) and dislocations (right pointer), and b) T3 showing well-connected grains.

$L_{g b}$ was determined by tracing the grain boundaries and determining the line length per area by image analysis. $L_{g b}$ is compared to $J_{c}(4 \mathrm{~T})$ in Fig. 4. Low field $J_{c}$ increased with grain boundary density.

\section{DISCUSSION}

$\mathrm{SnMo}_{6} \mathrm{~S}_{8}$ samples of good quality were produced. The $T_{c}$ values are up to $14.3 \mathrm{~K}$, which is good for materials

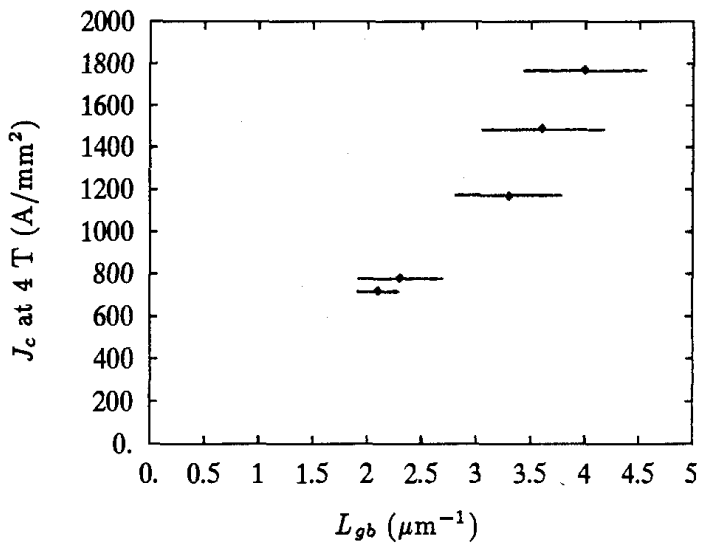

Figure 4: $J_{c}$ dependence on grain boundary line length per unit area, $L_{g b}$.

processed in quartz, which can contaminate samples with oxygen. [10] The narrow transition width indicates good sample quality and phase purity. The depressions of $T_{c}$ observed in T2 and T3 are unexplained. However, the samples were heat treated in quartz and, presumably, their lower $T_{c}$ values reflect oxygen contamination. Samples T1 and $\mathrm{T} 4$ were not contaminated by these heat treatments. The small shift in $T_{c}$ with $B_{a c}$ is comparable to shifts observed in single crystal CP [11] which indicates that these polycrystalline sample are not plagued with weakly coupled grain boundaries.

$J_{c}$ values obtained in this work are high for bulk CP, in general, but especially for $\mathrm{SnMo}_{6} \mathrm{~S}_{8}$, which has a lower $B_{c_{2}}$ than $\mathrm{PbMo}_{6} \mathrm{~S}_{8}$. At $8 \mathrm{~T}, J_{c}$ of the as-HIP'ed sample was $900 \mathrm{~A} / \mathrm{mm}^{2}$, which is as high as the best values so far reported for any CP. Anomalous jumps in $J_{c}$ at fields below $2 \mathrm{~T}$ are the result of flux jumps, which also indicate good sample connectivity. Furthermore, the values of $\Delta H / 3 \Delta M \sim 1$ for all samples indicate the well-connected nature of the samples. At fields $<8 \mathrm{~T}$ the drop in $J_{c}$ with increasing anneal time and temperature suggests that pinning defects are being annealed to a lower density. The drop in $J_{c}$ values of T2 and T3 below that of T4 at higher fields is probably an effect of their depressed $T_{c}$ and $B_{c_{2}}$ values.

Although, post-HIP-annealed samples appear to be nearly single-phase by XRD, SEM analyses show them to contain phases other than CP at no more than a few volume percent. The Mo-containing phase, which appeared bright by SEM-BEI, was observed in all samples, although to a lesser extent in the two samples annealed at $1150^{\circ} \mathrm{C}$. This phase is identified as Mo, which has a higher average atomic number than $\mathrm{SnMo}_{6} \mathrm{~S}_{8}$. All molybdenum sulfide phases have a lower average atomic number than $\mathrm{SnMo}_{6} \mathrm{~S}_{8}$ and would, therefore, appear darker. The phase that appeared darker and striated by BEI of samples annealed at 
$\leq 1000^{\circ} \mathrm{C}$ is believed to correspond to the striated phase observed in TEM. This phase, from which Mo and $S$ were detected by EDX, is believed to be $\mathrm{MoS}_{2}$, which has a layer structure. Samples annealed at $1150^{\circ} \mathrm{C}$ may contain $\mathrm{MoS}_{2}$ or $\mathrm{Mo}_{2} \mathrm{~S}_{3}$ phases, but darker contrast in BEI images may result only from surface relief due to polishing.

All samples exhibited a wide range of grain sizes from a few nanometers to a few micrometers. $L_{g b}$ fell between 2 and $5 \mu \mathrm{m}^{-1}$, corresponding to average grain sizes between 0.2 and $0.5 \mu \mathrm{m}$. The large uncertainty in these values comes from the large distribution of grain sizes within each sample. Decreasing values of $L_{g b}$ with thermal treatment gave corresponding decreases in $J_{c}$ values. This result is evidence for grain boundaries being pinning centers for Abrikosov vortices. The role of intragranular defects in flux pinning cannot be distinguished from that of grain boundaries in the present results because the density of these defects would be expected to decline with annealing, as well. Results are, however, consistent with grain boundary pinning.

\section{SUMMARY}

Well-connected SMS samples with different microstructural defect densities were made by annealing HIP'ed samples at $1000^{\circ} \mathrm{C}$ and $1150^{\circ} \mathrm{C}$. Microstructural analyses showed that $L_{g b}$ dropped with increased heat treatment time and temperature. Electromagnetic analyses showed that all samples were well-connected. Critical current densities dropped with more aggressive heat treatment, which lowered $L_{g b}$. We conclude that higher $J_{c}$ can be achieved in CP by (1) avoiding oxygen contamination, (2) HIP'ing for densification, and (3) using lower heat treatment times and temperatures in order to preserve high grain boundary density.

\section{ACKNOWLEDGEMENTS}

The authors thank Drs. L. Le Lay, A. U. Umezawa and A. Gurevich of the Applied Superconductivity Center and Dr. D. G. Hinks of Argonne National Laboratory for useful discussions, and R. Casper of the Materials Science Program for experimental assistance. This work was funded by the U.S. Department Of Energy, Division of High Energy Physics and Office of Fusion Energy.

\section{REFERENCES}

[1] International Workshop on Chevrel Phase Superconductors, Hôtel de Chavannes-de-Bogis, Switzerland, September 1991. Procedings ed. by M. Decroux, U. of Geneva, Switzerland.

[2] B. Seeber, M. Decroux and $\emptyset$. Fischer, "Status and prospects of superconducting Chevrel phase wires for high magnetic field applications," Physica B, vol. 155, pp. 129-135, 1989.
[3] D. Cattani, J. Cors, M. Decroux and $\emptyset$. Fischer, "Intra- and intergrain critical current in $\mathrm{PbMo}_{6} \mathrm{~S}_{8}$ sintered samples," IEEE Trans. Mag., vol. 27, pp. $950-953,1991$.

[4] H. Yamasaki, M. Umeda, S. Kosaka, Y. Kimura, T. C. Willis, and D. C. Larbalestier, "Poor intergrain connectivity of $\mathrm{PbMo}_{6} \mathrm{~S}_{8}$ in sintered Mosheathed wires and the beneficial effect of hotisostatic-pressing treatments on the transport critical current density," J. Appl. Phys., vol. 70, pp. 16061613, 1 August 1991.

[5] L. Le Lay, T. C. Willis, and D. C. Larbalestier, "Fully connected bulk $\mathrm{Pb}_{1-x} \mathrm{Sn}_{x} \mathrm{Mo}_{6} \mathrm{~S}_{7.6}$ samples made by hot isostatic pressing," Appl. Phys. Lett., vol. 60, pp. 775-777, 10 February 1992.

[6] V. R. Karasik, M. O. Rikel', T. G. Togonidze, and V. I. Tsebro, "Investigation of current-carrying capacity of bulk single-phase $\mathrm{PbMo}_{6} \mathrm{~S}_{8}$ samples with grains of $\approx 0.1 \mu$ size," Sov. Phys. Solid State, vol. 27, pp. 1889-1890, October 1985.

[7] C. Rossel and $\emptyset$. Fischer, "Critical currents in bulk Chevrel-phase samples," J. Phys. F:Metal Phys., vol. 14, pp. 455-472, 1984.

[8] D. W. Capone II, R. Guertin, S. Foner, D. G. Hinks and H.-C. Li, "Effect of pressure and oxygen defects in divalent Chevrel-phase superconductors," Phys. Rev. B, vol. 29, pp. 6375-6377., June 1984.

[9] H. Küpfer, C. Keller, A. Gurevich, K. Salama, and V. Selvamanickam, Proc. 3rd Int. Symp. Superconductivity (ISS 90), Sendai, Japan, November 1990; in Advances in Superconductivity III, eds. K. Kajimura and H. Hayakawa, Tokyo: Springer-Verlag, 1991, pp. 709-714.

[10] P. Selvam, D. Cattani, J. Cors, M. Decroux, Ph. Niedermann, S. Ritter, $\emptyset$. Fischer, P. Rabiller, R. Chevrel, L. Burel, and M. Sergent, " $T_{c}$ variation in $\mathrm{PbMo}_{6} \mathrm{~S}_{8}: \mathrm{A}$ critical analysis and a comparison with pure phases," Mat. Res. Bull., vol. 26, pp. 1151-1165, 1991.

[11] M. Decroux, D. Cattani, J. Cors, S. Ritter, and $\emptyset$. Fischer, "Granular behavior of $\mathrm{PbMo}_{6} \mathrm{~S}_{8}$ Chevrel phase," in Proceedings of LT-19, Brighton, 1990. 